\title{
Cervical Cancer Screening In Benin City, South-South Nigeria
}

\author{
Obaseki D E ${ }^{1}$, Nwafor $\mathrm{C} \mathrm{C}^{2}$ \\ Department of Morbid Anatomy, University of Benin Teaching Hospital, Benin City, Edo State, Nigeria.
}

\begin{abstract}
This study is to evaluate the cytopathological profile of cervical smear of women that came for voluntary screening at the University of Benin Teaching Hospital, from August 2008 -to July 2012. A total of 3,284 cervical smears were done during the study period with age range of 15-89yrs. There were 2,021 (61.5\%) normal smears, 478 (14.6\%) inflammatory smears, 533 (16.2\%) abnormal epithelial lesions (squamous and glandular lesions) and $232(7.7 \%)$ unsatisfactory smears. Of the premalignant lesions, LSIL accounted for $74.1 \%$ of them with the majority of them (48.6\%) occurring in the age group 50-59years. The major finding of this study is the relatively high rate of premalignant/malignant lesions (16.2\%) in comparison to those reported from the western world and other developing countries. Since this is the first study of this kind in our centre, it means that more emphasis should be placed on routine screening and patients found to be positive for premalignant lesions should be managed seriously and closely monitored. Preventive vaccine should also be given to females less than 13 years of age, since this study shows that the pattern of cervical screening in our environment is not favorable.
\end{abstract}

Key words: Cervical Cancer, Screening

\section{Introduction}

Cervical cancer is the second most common cancer in women constituting about $12 \%$ of all cancers in women worldwide. There 452,000 new cases recorded each year, with more than 234,000 deaths occurring from it each year. ${ }^{1}$ The majority of these cases occur in developing countries. It is the commonest cancer in females in developing world. ${ }^{2}$ Yet, cervical cancer is one of the few cancers that is both curable and preventable. About $80 \%$ reductions in mortality and morbidity have been achieved in many developed countries. ${ }^{3}$

Since cervical cancer is preventable and takes a long time to develop, its incidence and mortality has been reduced by effective screening programs in developed countries. ${ }^{2}$ Various screening methods are available like visual inspection with acetic acid (VIA) and human papilloma virus (HPV) DNA testing, but the most successful in reducing incidence and mortality is screening by cervical cytology (Papanicolaou (pap) smear). ${ }^{3}$ Pap smear, though introduced in the 1940s, has become a widely accepted cancer screening test. ${ }^{4}$ In most industrialized nations, because of routine cervical screening (pap smear) the incidence of cervical cancer has decreased substantially.

Globally, eighty percent of new cases of cervical cancer occur in developing countries, conversely only $5 \%$ of women in these countries have ever had cervical cytology (Pap) smear. ${ }^{3}$ Cervical smear is so useful, such that it is the standard by which all other approaches for cervical cancer screening are judged. ${ }^{3}$

Cervical screening programs have been reported in few centres in Nigeria, many of which are in South-Western part and South-Eastern part of Nigeria. ${ }^{5-8}$ This study is a prospective study from August 2008 July 2012. The aim of this study is to evaluate the cytopathological profile of cervical smear of women that came for voluntary screening in a teaching hospital setting in Benin City, South-South Nigeria. The University of Benin Teaching Hospital (UBTH) is the only teaching hospital in Benin City, Nigeria. It renders service to inhabitants of Benin City and neighbouring towns.

\section{Materials and method}

This is a prospective study involving all females that came for cervical cancer screening performed in UBTH between August 2008 to July 2012. The women all visited the clinic for voluntary check up and cervical smear was newly introduced as part of the health checks. The majorities of them were doing it for the first time, while any woman with a history of cervical lesion or symptom was referred to gynecology clinic and were not included in this study.

All the smear were collected by specially trained nurses and health assistants, with the use of a speculum and Ayre's wooden spatula with which the ectocervix and endocervix is scraped in a complete circle in one sweep (360 degrees). Scrapings were immediately applied on glass slides to make a smear. This was done twice, to produce two slides that are immediately fixed in 95 percent alcohol for $15=30$ minutes. The fixed smear are stained by the cytotechnologist using Papanicolaou stain and read by the histopathologist using a light microscope. The slides were reported as normal, inflammatory, abnormal (epithelial lesion) or unsatisfactory. The abnormal ones were classified using the Bethesda 2001 system into the following: ${ }^{9}$ 
- Atypical squamous cells of undetermined significance (ASCUS)

- Atypical squamous cells high grade lesion cannot be ruled not (ASCH)

- Low grade squamous intraepithelial lesion (LSIL)

- High grade squamous intraepithelial lesion (HSIL)

- Squamous cell carcinoma

- Atypical endocervical cells not otherwise specified

- Atypical endocervical cells favor neoplastic

- Endocervical adenocarcinoma insitu

- Adenocarcinoma.

\section{Results}

A total of 3,284 cervical smears were done during the study period. There were 2,021 (61.5\%) normal smears, 478 (14.6\%) inflammatory smears, $533(16.2 \%)$ abnormal epithelial lesions (squamous and glandular lesions) and $232(7.7 \%)$ unsatisfactory smears as seen in Table1.

The ages of screened women ranged from 15-89years, with a mean age of 46.1 years. Majority of the screened women were between the ages of 50-59 years $(1078=32.9 \%)$ and $40-49$ years $(103=31.4 \%)$. Women in the age groups 30-39 years, 60-69 years, 20-29 years, 70-79 years, 80-89 and less than 19 years accounted for $625(19.0 \%), 290(8.8 \%), 234(7.1 \%), 13(0.4 \%), 7(0.2 \%)$ and $5(0.2 \%)$ respectively as seen in Table 2.

Table 3 shows the distribution of lesions according to the Bethesda 2001 system. ${ }^{9}$ Majority of the abnormal epithelial lesion were in the LSIL grade, $393(12.0 \%)$. Others are HSIL, ASCUS, Atypical endocervical cells not otherwise spercified, ASCH, Squamous cell carcinoma, Atypical endocervical cells favour neoplastic, Adenocarcnoa institu and Adenocarcinoma which accounted for 85 (2.6\%), $19(0.6 \%), 16(0.5 \%), 12(0.4 \%) 3$ $(0.1 \%), 3(0.1 \%), 1(0.0 \%)$ and $1(0.0 \%)$ respectively.

TABLE 1

\begin{tabular}{lll}
\hline Outcome & Frequency & Percentage (\%) \\
\hline Normal & 2021 & 61.5 \\
Inflammatory & 478 & 14.6 \\
Abnormal & 533 & 16.2 \\
Unsatisfactory & 252 & 7.7 \\
Total & 3284 & 100 \\
\hline
\end{tabular}

TABLE 2

\begin{tabular}{lll}
\hline Age group & Frequency & Percentage \\
\hline $15-19$ & 5 & 0.2 \\
$20-29$ & 234 & 7.1 \\
$30-39$ & 625 & 19.0 \\
$40-49$ & 1031 & 31.4 \\
$50-59$ & 1079 & 32.9 \\
$60-69$ & 290 & 8.8 \\
$70-79$ & 13 & 0.4 \\
$80-89$ & 7 & 0.2 \\
TOTAL & 3284 & 100 \\
\hline
\end{tabular}

TABLE 3

\begin{tabular}{llllllllll}
\hline Diagnosis & \multicolumn{1}{c}{ Agegroup } \\
\hline & $15-19$ & $20-29$ & $30-39$ & $40-49$ & $50-59$ & $60-69$ & $70-79$ & $80-89$ & TOTAL \\
\hline Normal & 5 & 186 & 439 & 664 & 586 & 129 & 10 & 2 & 2021 \\
Cervicitis & 0 & 33 & 96 & 163 & 137 & 47 & 0 & 2 & 478 \\
ASCUS & 0 & 1 & 5 & 4 & 7 & 2 & 0 & 0 & 19 \\
ASCH & 0 & 0 & 1 & 5 & 4 & 2 & 0 & 0 & 12 \\
LSIL & 0 & 5 & 30 & 93 & 191 & 71 & 2 & 1 & 393 \\
HSIL & 0 & 0 & 3 & 22 & 45 & 14 & 0 & 1 & 85 \\
SCC & 0 & 0 & 0 & 2 & 0 & 1 & 0 & 0 & 3 \\
Aty,E,NOS & 0 & 1 & 4 & 3 & 6 & 2 & 0 & 0 & 16 \\
Aty,E,Neop & 0 & 0 & 0 & 2 & 0 & 1 & 0 & 0 & 3 \\
AdenocaInsitu & 0 & 0 & 0 & 0 & 1 & 0 & 0 & 0 & 1 \\
Adenocar & 0 & 0 & 0 & 0 & 1 & 0 & 0 & 0 & 1 \\
Unsatisfactory & 0 & 8 & 47 & 73 & 101 & 21 & 1 & 1 & 252 \\
TOTAL & 5 & 234 & 625 & 1031 & 1079 & 290 & 13 & 7 & 3284 \\
\hline
\end{tabular}




\section{Discussion}

Based on the over whelming evidence supporting the incidence, morbidity and mortality of cancer of the cervix, there should be an effective screening program aimed at detecting precancerous lesions of the cervix before the progress to cancers. The best screening method for cervical cancer remains cytological examination using pap smear. ${ }^{3}$

In the absence of a coordinated National or regional cervical cancer screening program in Nigeria, UBTH, a tertiary health centre that serves the Midwestern region in South-South Nigeria commenced a scheme for cervical smear screening in August 2008. The program was initially opened to the more than 2,000 female staff members of the hospital and it was free of charges for the first 6months. Subsequently, it was made available to the general public at a minimal (subsidized) fee.

Our study, a review of the first four years of this program, showed that there were $16.2 \%$ premalignant and malignant lesions, $14.6 \%$ inflammatory lesions, 61.5\% normal smears (lesion negative) and $7.7 \%$ unrepresentative/unsatisfactory smears. Of the premalignant lesions, LSIL accounted for $74.1 \%$ of them and majority of them $191=48.6 \%$ occurred in age group 50-59years.

Studies of cervical screening in other parts of Nigeria show similarity in some aspects, with the findings in our study. Studies in Ibadan, Enugu and Nnewi reported normal smear (Lesion negative) rates of $55.3 \%, 88 \%$ and $58 \%$ respectively. ${ }^{5,7}$ An inflammatory smear rate of $14.6 \%$ in our study is low compared to $52.7 \%$ and $35.6 \%$ reported in Lagos and Ibadan respectively. ${ }^{5,6}$ This may be due to the small sample size in Lagos, and also pathologists bias as to what quantity/extent of presence of inflammatory cells in a cervical smear constitute an infection.

The rate of premalignant/malignant lesion in our study (16.2\%) is high, compared to $5.0 \%$ and $8.4 \%$ in studies in Lagos and Ibadan but its comparable to the $12.2 \%$ in Enugu. ${ }^{5,6,7}$ The relatively higher prevalence of abnormal epithelial lesions in the present study maybe due to the disproportionate number of women in the age groups of 30-59 (83.3\%) in the present study. The prevalence of pre-invasive and invasive epithelial lesions of the cervix is highest in this age range. ${ }^{10}$ So selectively screening this group will yield a higher pickup rate of abnormal epithelial lesions.

Another reason for the high number may be because, when the cervical screening program in UBTH was commenced in 2008, it was initially made free for all staff of the hospital for six months. This also accounted for the disproportionately high number of women in the age range of 30-59yrs, which constitutes the prime and majority working age group.

Studies, in South Africa, ${ }^{11}$ Saudi Arabia,${ }^{12}$ india $^{13}$ and United states of America ${ }^{14}$ are all at variance with the present study. The rates of premalignant/malignant lesions in all the above listed countries are $4.69 \%$, $4.95 \%, 5.5 \%$, and $5.0 \%$ respectively. Also at variance with our study is a normal smear rate of $94.5 \%$ in USA, which helps to explain that routine screening and other preventive measures when implemented, helps to achieve great results. ${ }^{14}$

The rates of inflammatory smear in Saudi Arabia ${ }^{12}$ and india ${ }^{13}$ are high $(48.3 \%$ and $57.4 \%)$ when compared to that in our study (14.6\%), but the rate of premalignant lesion in our study may be a guide to the fact that other co- carcinogens apart from infections may abound in our environment and may be responsible for the high rate of premalignant lesions.

Since this is the first study of this kind in our centre, it means that more emphasis should be placed on routine screening and patients found to be positive for premalignant lesions should be managed seriously and closely monitored. Preventive vaccine should also be given to females less than 13 years of age, since this study shows that the pattern of cervical screening in our environment is not favorable.

\section{Conclusion}

The pattern of cervical smear in Benin City, Edo State has been documented and our findings are particularly revealing. The high number of women that turned out for screening is commendable and indicates a heightened awareness of cervical cancer. Also this study will serve as a background data for future cervical smear studies in Edo State. However serious efforts should be made to follow up women that have premalignant lesions.

\section{References}

[1] Parkin DM, Pisani P and Ferlay J. Estimates of the worldwide incidence of 25 major cancers in 1990. Int. J. Cancer, 1999; 80, 827841.

[2] Symonds RP. Screening for cervical cancer: different problems in the developing and the developed world. Eur J cancer care. 1997; 6(4): 272-279.

[3] Miller AB, Nazeer S, Fonn S, Brandup-Lukanow A, Retiman R etal. Report on consensus conference on cervical cancer screening and management. IJC 2000; 86 (3): 440-447.

[4] Sirovich BE. Cervical cancer screening among women without a cervix. JAMA 2004; 291 (2): 2990-2993.

[5] Konje JC, Ogunniyi JO, Otolorin E.O, Odusoga OL, Ogunlusi MO. Cervical cancer screening at Ibadan. Eur J. Gynaecol oncol. 1991; 12(1): 55-61. 
[6] Anorlu RI, Abdul-kareem FB, Abudu OO, Oyekan TO. Cervical cytology in an urban population in Lagos, Nigeria. J. Obstet gynaecol. 2003; 23 (3): 28-8.

[7] Chukwudi LI, Onuigbo WIB, Mgbor NC. Trop J Obstet Gynaecol. 2003;20: 109-112.

[8] Nwosu OB, Okafor CI, Obiechine NJ, Odike MA. The pattern of cervical cytology in Obstetrics and gynaecology clinics in Nnewi, South-Eastern Nigeria. OJM 2010; 22 (1-4): 25-28.

[9] The 2001 Bethesda system; Terminology for reporting results of cervical cytology. JMA 2002;287, 2114

[10] Ellenson LH and Pirog EC. The female genital tract. In Kumar V, Fausto N, Aster J, Abbas A (eds): Robbins and Cotran Pathologic basis of disease. $8^{\text {th }}$ Ed. Elsevier India 2010, pp $1005-1063$.

[11] Fonn S, Bloch B, Mabina M, Carpenter S, Cronje S eta al. Prevalence of pre-cancerous lesions and cervical cancer in South Africa -a multicentre study. S Afr Med. J. 2002; 92(2): 148-56.

[12] Balaha MH, Moghannum MS, Ghowinen NA, Omran SA. Cytological pattern of cervical papanicolaou smear in eastern region of Saudi Arabia. J. Cytol. 2011; 28 (4): 173-177.

[13] Patal MM, Pandya AN, Modi J. Cervical Pap smear study and its utility in cancer screening, to specify the strategy for cervical cancer control. National journal of community medicine $2011 ; 2(1)$ : 49-59.

[14] Insinga RP, Glass AG, Rush BB. Diagnoses and outcomes in cervical cancer screening: a population -based study. Am J Obstet Gynacol. 2004; 191(1): 105-13. 